\title{
Developing Reprocessing and Packing of the Rural Special Products and Revitalizing the Rural Economy through E-Commerce
}

\author{
Li Dan \\ Associate professor \\ Liaoning Institute of Science and Technology \\ Benxi, China
}

\author{
Wang Hongwei \\ Hr manager \\ Benxi Branch of China Life Insurance Co. LTD \\ Benxi, China
}

\begin{abstract}
Huanren county of Benxi is rich in lots of rural special products, such as "Daohuaxiang Rice". But at the same time, it is accompanied by extreme poverty. The purpose of this paper is to solve the problem of poverty by using modern technology such as big data and the Internet. The main emphas is placed on the problem is to incorporate e-commerce into agricultural industry. Through website, the reprocessed and packed rural products can reach throughout the world and the farmers can get symmetrical information to improve the production. The paper demonstrates the significance to link rural special production with the Internet. The paper discusses the technological problems in the process to establish the website and the difficulty in the improving product competitiveness. A new agricultural ne twork platform integrating supply, marketing and information interaction can increase the sale of the rural products and also provides information to the farmers about the production. Compared with the traditional sale, the new business models can increase the farmers' income to achieve accurate poverty alleviation.
\end{abstract}

Keywords—network, big data, special products, websites sales circulation

\section{INTRODUCTION}

The decision of the state council of the CPC central committee "On Winning the Tough War against Poverty" was released in November 2015. Efforts from the society are intensified to develop the rural economy through the Internet and implement e-commerce to assist rural development. In November 2016, the state council issued the "The 13th Fiveyear Plan for Anti-poverty Battle.” in which electricity will be an important channel the revitalization and the development of agricultural industry. It requires that the rural electronic commerce should be taken as an important carrier of rural economy development and the electronic commerce should be incorporated into rural economic development work system. Electricity and electric business platform enterprises are encouraged and guided to set up characteristic agricultural products online sales platform. The paper takes Huanren County Liaoning Province as the research object. By using big data to develop fine native products processing and packaging industry and Internet for sales, farmers can achieve to increase income.

Focusing on the whole village in Huanren County 6,000 poor people as the key object, the key link is that fine processing and packing of rural special products can be utilized as the core, through the electric dealer market operation. A basic complete set can be formed, and demonstration can be promoted. The Rice "Daohuaxiang" in Huanren County is renowned throughout the country and was once known as "Imperial Rice” .And it is sold for 3 Yuan per catty. The average annual production of rice in Huanren is 5000 catty in simple packing bags which contain $25 \mathrm{~kg}$ each. Six Yuan per kilogram, annual output is fifteen thousand. But special products which contain ten catty per fine box is worth 85 Yuan. The product packaging is removed and rice remains 12 Yuan per kilogram. Compared with the original packing of rice, the price has been doubled, which can create more profit of fifteen thousand each year. With the establishment of the Internet, at the same time the characteristics of agricultural products such as native eggs, soil Hun Jiang carp, ice grapes, wild mushrooms can be reprocessed, packed to be fine products before they are sold all-through the nation, but the price of the products is greatly increased. So does the income of farmers. At present, the rural infrastructure has improved. Modern optical fiber equipment has covered mountains above the hills. The paper targets that through the Internet technology, through the establishment of the website, after fine processing and packing of special products, the special products can be sold online to gain greater profits. Greater value can be created so as to achieve the purpose of increasing farmers' income.

\section{It IS OF Practical VAlUE AND SignificANCE TO ReProcess and PACK NATIVE PRODUCTS}

\section{A. The meaning about quality of agricultural products}

By using network technology, a big data platform is established to analyze large-scale production of special products in rural areas. By having improved the quality of products, production and price of special products conform to the standards. It is not only conducive to the improvement of agricultural production efficiency, but also to the improvement of the overall output quality of agricultural products.

\section{B. The meaning about boosting the rural economy}

Through developing fine processing and packing of local products, the farmers income is increased, which can effectively solve the problem of rural poverty. The paper aims to alleviate the urgent problems of the poor, and at the same 
time promote the funding growth to economy so as to promote the new rural construction.

\section{The meaning about satisfying the need for the rural products}

After the establishment of big data platform and the establishment of supply and demand link platform, special products of Huanren meet with the demanders on the Internet. And a supply and demand system can be established by using optical equipment and the Internet.

\section{The meaning about using modern technology}

Using big data to analyze problems such as the use of infrastructure, the packing of special products and the comparison of profits respectively, solutions can be proposed.

\section{E. The meaning of guidance to other rural places}

This sales method will become the dominant one. Timely summarize and exchange the experience and then continuous innovation about the production, processing and packaging model can be improved. The paper explores new marketing mode. They also provide reference for other parts of the agricultural economy. The researchers can conclude that the countermeasures of enlightenment for the future perfect the northeast rural economic construction, providing guiding significance to improve agricultural production and sale.

\section{Try to Promote Plan and Make Farmers Understand} the Purpose and Participate in It to Help Farmers ACHIEVEMENT OWN ENTREPRENEURIAL DREAMS

\section{A. In-depth investigation and understanding of the production and sales of traditional agricultural products}

Taking Huanren County as the research object, questionnaire survey was conducted on local farmers by means of field investigation, household survey and panel interview, and in-depth understanding were approached to form a research report. Big data is used to analyze the production of native products.

\section{B. Setting up acquisition network and classifying agricultural products}

The researchers rent Huanren idle farm as purchasing network. They hire local farmers to collect rice and agricultural products, classify, inspect the agricultural products quality, and then put the label of price on the products in the center of classification.

\section{Fine processing to improve product grade}

Purchasing precision processing equipment and inviting experts to guide farmers in precision processing, the researchers in sorting center carries out precision processing and packaging of rice and other products.

\section{Improving product competitiveness by exquisite packaging design}

With the container, the researchers design products with local characteristics, provide product grades, design English packaging containers. At the same time, they sell products to the international market. They help farmers by break traditional trading information transmission barriers and exchange limitations of time and space on depend of the website. It is helpful to form a unified and orderly market to make the farmers into trans-regional and transnational sales network.

\section{E. Accurate understanding of market demand is used to guide the production of farmers}

Through the establishment of the website, the researchers reduce or even eliminate agricultural market information asymmetry phenomenon of production for farmers. Provided comprehensive information to offer aid in the production, farmers can accurately grasp the market demand and make intelligent agricultural production behaviors.

\section{F. Helping farmers expand sales circulation by using big data analysis and comparison}

The researchers analyze and compare production and sales with big data to help farmers realize large-scale agricultural products circulation. The adoption of online trading platform in agricultural e-commerce enables the large-scale and organization of a small number of individual agricultural products transactions.

\section{G. Establish sales model to expand sales}

A business model can be established. By setting up a website to sell agricultural products, the researchers can also enter Tmall and other international websites, sign contracts and sell agricultural products.

\section{The Technological Problems We Face}

\section{A. Problems to be solved from the aspect of e-commerce}

How to incorporate the electronic commerce into the agricultural industrialization? From the information on web site, processing orders, production to be arranged, allocation of resources, in nearly all organizations in the supply chain can be obtained the "first time" from the Internet. How to obtain the required information, how to reduce cost and how to link transaction with production, how to save cost are all to be concerned to improve the economic benefit need to be concerned.

\section{B. Problems to be solved from the product quality}

How to unify the agricultural product quality inspection, how to classify, how to take the plain code marks a price guarantee the quality of circulation scale in the process of agricultural products, how to pack rice and other products through the processing technology helped make the similar products into the boutique are all question to be concerned.

\section{The technical problem of communication websites reducing time space}

How to use the Internet to help farmers to break the traditional trade in information transmission and exchange of time and space limit , through the trade on the website of ,how do we help the farmers into trans-regional and transnational sales network to form a unified and orderly market also need to be concerned. 


\section{Problem of supply and demand to be solved by using big data and Internet}

How to use the Internet and big data technology to solve the local agricultural products circulation system which is not yet complete, how to solve the problem that product sales channels are narrow, and how to solve the problem that transaction costs are high and how do we solve the problem that supply and demand chain is seriously divided should be concerned.

\section{In Order to Solve These Problems, We Did the FOLLOWING}

\section{A. Building a website to enhance farmers' understanding \\ The researchers created websites to enhance the influence of communication platforms. They will increase publicity on the platform for the entrepreneurship and exchange for fine processing packaging, and increase the influence of the Internet on farmers so that these platforms can truly benefit farmers.}

\section{B. Providing standardized business services to customers}

They provided customers with agricultural products supply and purchase information, merchant certification, specialty stores, agricultural products prices and other whole-process ecommerce services.

\section{Establish the equivalent transaction model to serve}

The research supports online listing, online negotiation, bidding and other trading modes, including trading system, information system, office system and recharge system.

\section{Setting up a trading platform for enterprises and farmers}

The research ensured that farmers and enterprises can gain access to the platform through mobile phones and computers to realize agricultural products information release, online agricultural products trading and information management of agricultural products enterprises.

\section{Yet,There Are Still Some Difficulties to BE Conquered. In View of These Difficulties, We Have TAKen Corresponding Measures to Make Our SpeCial PRODUCTS WIN IN QUALITY}

A. The way to solve the difficult to keep the quality of similar products ahead

The quality of rice should be strictly controlled. Competition from similar products: one of the most famous is the WuChang Rice in Harbin, northeast rice of Mudanjiang Xiangshui Rice, tender Matsubara Rice, Jilin Rice and Liaoning Panjin Rice, on the other hand, also world-famous Tianjin Station Rice. No matter what kind of good rice, it is inseparable from its specific growth environment and climate conditions, and the output of the absolutely authentic good rice is quite limited[3]. Wu use big data to guide rice production. The paper gives guidance to farmers to avoid the use of pesticides, herbicides, in particular, in seedling stage and high nutrition, without any pesticide chemical fertilizer. "Organic rice seedling matrix", river floodplain soil, humus soil and lime soil in the forest plus a variety of nutrients, according to the proportion of nutrition matching a specially used in seedling stage of organic soil are all conditions for the rice we collect[1].
Organic soil nutrition proportion is more reasonable, more suitable for the growth of rice seedlings. And, at the time of planting rice in Huairin we insist on using only the best rice seedlings, plant height $15 \sim 18$ centimeters, root number 13 20 , so tall, handsome seedlings can eventually produce crystal and jade of the big grain of rice[4]. When transplanting rice seedlings, they also adhere to the strictest organic standards and realize the best field management and planting combined with modern agricultural technology. Only a reasonable density can ensure that each seedling has the best growth space and thus produces the fullest rice[2].

\section{$B$. The way to solve the difficulties of E-commerce}

By setting up different agricultural e-commerce mode and solving the different problems existing in the current agricultural trade, the research has different network adaptability. Value chain integration and the third party trading market can effectively solve the problem which agricultural products trade links too much. Information is open and transparent to standardize the behavior of the parties. The four model specification of the trading process ,the online store, electronic procurement, value chain integration, third-party trading market and scientific way to trade about shing trading irregularities exist in the traditional trading become less stubborn. Website has function of information collection, distribution[5].

\section{The difficult way to solve the information asymmetry}

The researchers adopt the model of the enterprise in order to gather popularity and provide perfect services, strengthen the information service ability, and make the participants get more comprehensive related transaction information and, to a certain extent. Eliminate information asymmetry. Information intermediary mode can effectively reduce the cost of collecting information in agricultural products transactions. Electronic stores, electronic procurement, value chain integration, thirdparty trading markets can be different degrees of honesty lower transaction costs. The third-party trading market model, through effective online trading means and contract trading can reduce the trading volatility. At the same time, according to the characteristics of large agricultural products trading volume, seasonal production and regional production, the platform also has different model adaptability.

\section{The Special Products are Sold on The INTERNET \\ After Processing and Precision Packing, With the FOLLOWING ADVANTAGES ,UNIQUENESS AND INNOVATIONS}

\section{A. The advantages of agricultural network platform on povertyalleviation}

The business model is applied to the emerging "Internet +" targeted poverty alleviation model. Building supply, sales, information exchange in the integration of new agricultural network platform, setting up business model, and effectively improving the grade of the product, the researchers use the Internet to achieve accurate poverty alleviation. The researchers use the Internet to emerging technologies boost poverty object ability of self-development. "Internet + " tools and big data have greatly improved the poverty alleviation effect. Application of large data analysis helps us understand the current supply and demand relations. The research of data 
for poverty alleviation can improve the analysis of data and applications, and can solve the problem of low accuracy poverty, eventually let poverty alleviation work to become more transparent, efficient, accurate and comprehensive.

\section{$B$. The advantages of the Internet website on public welfare}

The Internet web site building, the fine processing and packaging of agricultural products have a share, remote and fast characteristics. It makes its demands and resources in the link, and it plays an important role in promoting poverty alleviation, public welfare, and professional development.

\section{CONCLUSION}

Developing agricultural products in a differentiated way, developing high-end markets, refining packaging, they utilize the English major and sell products to international markets through websites. On the one hand, they sell finely processed and packed products online which can eventually enlarge the sales of the rural special products, and then increase the farmers' income. On the other hand, they summarize timely our experiences according to the circumstance to adjust, and provide farmers support for production guidance and entrepreneurship practice.

\section{ACKNOWLEDGMENT}

"Internet + Poverty Alleviation - a Link to Love in the Sun Huanren county Wan Longbei village farmers poverty alleviation idea." College Students' Innovation and Entrepreneurship Project of Liaoning Province in 2018(20181140056)

\section{REFERENCES}

[1] Xu Weihua, Wu Xuefen, Zhang Yuanzhao; Application research of "3414" field fertility test model based on Excel [J].Modern agricultural technology"2012, 07

[2] [2]Liu Xiaomei, Guo Xiaoli, Liu Mingyim Li Li, Ren Jinping; "Advances in hybrid japonica rice research". [J]. Modern agricultural science and technology 2010, 24

[3] [3]Liu Pingying, Zhao Yan; "Study on the application index system of rice phosphate potassium fertilizer in Jiawang district, Xuzhou city” [J].Modern agricultural science and technology;2011, 17

[4] [4]Guo Ximin, Li Yanhui; "Effects of balanced fertilization on rice yield” [J].Modern agricultural science and technology;2010, 11

[5] [5]Wu Xiaoping "Discussion on innovative development of rural ecommerce in Anhui” [J]. Business era, 2010 (3) 